\title{
Modeling and Simulation of Voltage Source Inverter with Voltage Drop and Its Application for Direct Torque Control of Induction Motors
}

\author{
H. L. Bui ${ }^{1,2 *}$, Shoudao Huang ${ }^{1}$, D. C. Pham ${ }^{3}$ \\ ${ }^{1}$ College of Electrical and Information Engineering, Hunan University, China. \\ 2 College of Electrical Engineering, Hanoi University of Industry, Vietnam. \\ ${ }^{3}$ Department of Electrical Engineering, Industrial University of Ho Chi Minh City, Vietnam. \\ * Corresponding author. Tel.: +84 912188829; email: blhien@yahoo.com \\ Manuscript submitted October 1, 2016; accepted October 28, 2016. \\ doi: 10.17706/ijcee.2016.8.5.294-303
}

\begin{abstract}
Power electronics and electrical machines nowadays offer an extremely wide range of industrial applications. Their modeling and simulation are also a great interest to engineers. In some simulation applications, nonlinear of the power electronic devices is neglected due to its simplicity. Therefore, the performance of the control system obtained is not the same as experimental results. In this paper, a model of two-level three-phase voltage source inverter having its voltage drops is proposed. Then application to direct torque control of three-phase induction motors with the proposed model has studied. Finally, the simulation results are provided to verify the effectiveness of the proposed work.
\end{abstract}

Key words: Direct torque control, modeling and simulation, three-phase induction motor, inverter, voltage drop.

\section{Introduction}

Power electronics and electrical machines has been a major change in industrial applications in recent years [1]-[6], including electric, hybrid, and plug-in vehicles (EVs) in the automotive industry [7], photovoltaic (PV) [8] and wind energy conversion systems (WECS) in the renewable energy industry, [9] or high voltage direct current (HVDC) and flexible ac transmission systems (FACTS) [10]. Specially, two-level three-phase voltage source inverter (VSI) is considered as a mature technology and becoming an industrial standard for the demand for energy saving. Accordingly, application to VSI fed three-phase induction motors (IM) can be considered a valid solution for energy saving because these motors are a simple and rugged electrical machine with adaptation to several load situations, and low cost acquisition and maintenance.

Direct torque control (DTC) is one of the advanced control schemes for ac drives [4], [11]. It is characterized by simple control algorithm, easy digital implementation and robust operation. In recent years, direct torque control (DTC) strategies of induction motor (IM) drives have been widely implemented in industrial variable speed applications which it is one of the advanced control schemes for ac drives. Introduced in the middle of the 1980s, it is characterized by simple control algorithm, easy digital implementation and robust operation. Since then, several investigations carried out in order to improve the performance of the original DTC strategy. The major focused features are the uncontrolled switching 
frequency of the inverter and the high torque ripple resulting from the use of flux and torque hysteresis controllers [4].

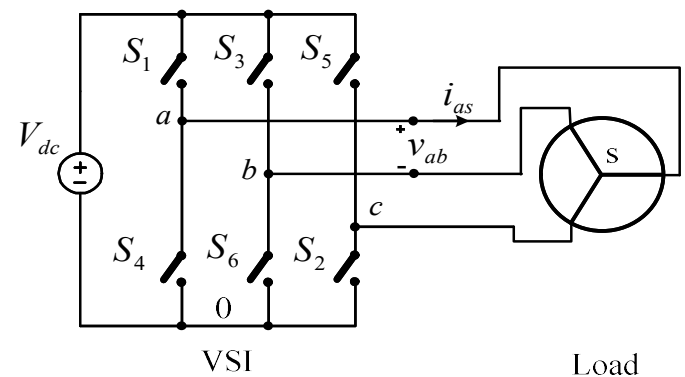

(a) An ideal voltage source inverter.

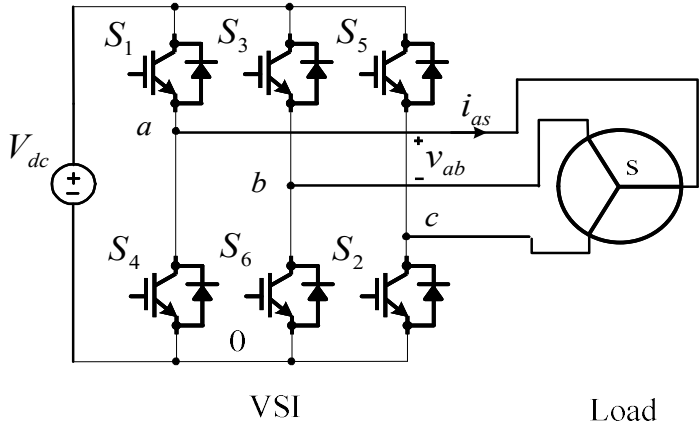

(b) A real voltage source inverter with IGBTs/Diodes.

Fig. 1. Voltage source inverter.

In some simulation applications, mainly the voltage drops of the power electronic devices (e.g. IGBTs, Diodes etc.) are neglected due to its simplicity [3]. Therefore, the performance of the control system obtained is not the same as the experimental results [12]. In order to overcome this, the model of a non-ideal two-level three-phase VSI (real VSI) is proposed in the paper. Then application to direct torque control of three-phase induction motors with the proposed model are studied.

The paper is structured so that a model of an idea inverter is reviewed in Section 2. Section 3 proposes a real inverter. A general description of the induction motor model is showed in Section 4. The direct torque control is discussed in Section 5, the simulation results are showed in Section 6, and conclusions are drawn in Section 7.

\section{Model of an Idea Inverter}

Fig. 1(a) shows an ideal two-level three-phase voltage source inverter (VSI) with six idealized switches, $S_{1}$ to $S_{6}$ and a dc constant voltage source $V_{d c}$ connecting a three-phase load. This inverter having the power devices is considered as ideal switches which there are no snubbers and gate drive circuits. Each phase leg of the VSI is represented by a "switch" that has three input terminals as follow:

$$
\begin{aligned}
& v_{a s}=v_{a 0}-v_{s 0} \\
& v_{b s}=v_{b 0}-v_{s 0} \\
& v_{c s}=v_{c 0}-v_{s 0}
\end{aligned}
$$

where $v_{\mathrm{as}}, v_{\mathrm{bs}}$, and $v_{\mathrm{cs}}$ are the phase-to-neutral voltages.

$$
v_{a s}+v_{b s}+v_{c s}=v_{a 0}+v_{b 0}+v_{c 0}-3 v_{s 0}
$$

Assuming that the system is balanced operation

$$
\begin{gathered}
v_{a s}+v_{b s}+v_{c s}=0 \\
v_{s 0}=\frac{v_{a 0}+v_{b 0}+v_{c 0}}{3} \\
v_{a s}=\frac{2 v_{a 0}-v_{b 0}-v_{c 0}}{3}
\end{gathered}
$$




$$
\begin{aligned}
& v_{b s}=\frac{2 v_{b 0}-v_{c 0}-v_{a 0}}{3} \\
& v_{c s}=\frac{2 v_{c 0}-v_{a 0}-v_{b 0}}{3}
\end{aligned}
$$

Equations (7)-(9) are model of an ideal VSI.

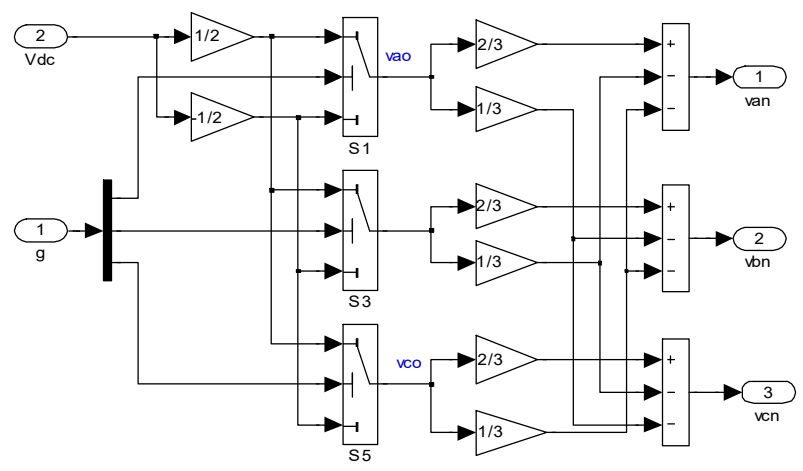

Fig. 2. MATLAB/Simulink model for an ideal VSI [3].

Fig. 2 shows MATLAB/Simulink model for an ideal VSI, including six idealized switches.

\section{Model of Real Inverter}

The power electronic devices (e.g. IGBTs, Diodes etc.) are nonlinear. It is well-known that the voltages drop of the power electronic devices causes distorted motor voltage and increasing motor current harmonic distortion, and reduction of the fundamental voltage/current component. This model includes the voltage drops in the IGBT switching devices and the freewheeling diodes which is shown in Fig. 1 (b). It is known that the instantaneous voltage drops of one converter leg presented by a switching device or a freewheeling diode can be represented by an on-state forward voltage drop connected in series with an on-state resistance. Thus, this voltage drop of one inverter leg can been calculated by Equation (10) [12]

$$
v_{\text {drop }}=v_{f}+R_{o n} i
$$

where $v_{\mathrm{f}}$ is the on-state forward voltage drop and $R_{\mathrm{on}}$ is the on-state resistance.

In addition, the inverter voltage drop on one inverter leg depends on both its instantaneous switching state and its relevant phase current direction. There are four cases considered as follows:

Case 1: if the current $i_{a s}$ flows to load $\left(i_{a s}>0\right)$ and the $\left(S_{1}=1\right)$ as shown in Fig. 3(a) then the terminal voltage $v_{a o}$ is defined by can been calculated as

$$
v_{a o}=V_{d c}-v_{i}=V_{d c}-v_{f i}-R_{o n i}\left|i_{a s}\right|
$$

where $v_{i}$ is the voltage drop of the IGBT; $v_{f i}$ and $R_{o n i}$ are the forward drop of IGBT, on-state resistance of IGBT, respectively.

Case 2: if $\left(i_{a s}<0\right)$ and the $\left(S_{1}=1\right)$ as shown in Fig. 3(b) then the terminal voltage $v_{a o}$ is defined by

$$
v_{a o}=V_{d c}+v_{d}=V_{d c}+v_{f d}+R_{o n d}\left|i_{a s}\right|
$$

where $v_{d}$ is the voltage drop of the Diode; $v_{f d}$ and $R_{\text {ond }}$ are the forward drop of Diode, on-state resistance of Diode, respectively.

Case 3: if the current $i_{a s}$ flows to load $\left(i_{a s}<0\right)$ and the $\left(S_{1}=0\right)$ as shown in Fig. 3(c) then the terminal voltage $v_{a o}$ is defined by 


$$
v_{a o}=v_{i}=v_{f i}+R_{o n i}\left|i_{a s}\right|
$$

Case 4: if the current $i_{a s}$ flows to load ( $\left.i_{a s}>0\right)$ and the $\left(S_{1}=0\right)$ as shown in Fig. 3(d) then the terminal voltage $v_{a o}$ is defined by

$$
v_{a o}=-v_{d}=-v_{f d}-R_{\text {ond }}\left|i_{a s}\right|
$$

Equations (7)-(9) and Equations (11)-(14) verify a mathematical model of a VSC having its voltage drop.

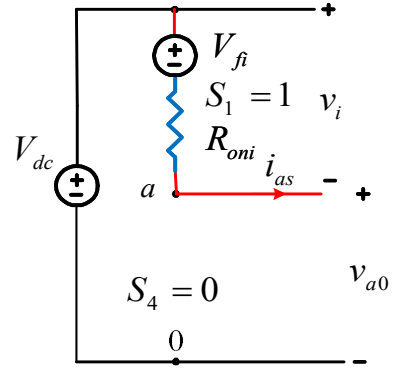

(a) $S_{1}=1$ and $i_{a s}>0$

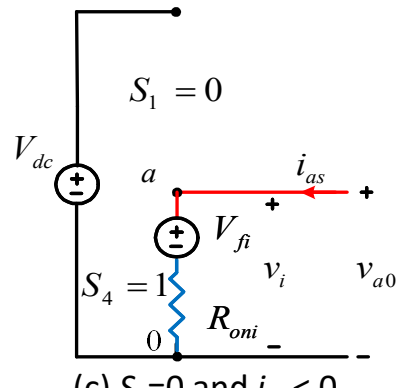

(c) $S_{1}=0$ and $i_{\text {as }}<0$

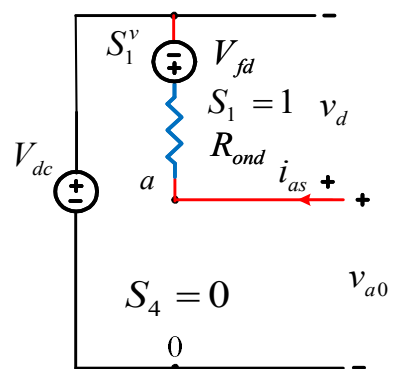

(b) $S_{1}=1$ and $i_{a s}<0$

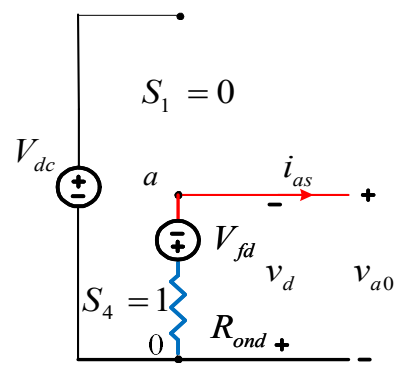

(d) $S_{1}=0$ and $i_{a s}>0$

Fig. 3. Analysis of each phase leg for a proposed VSI.

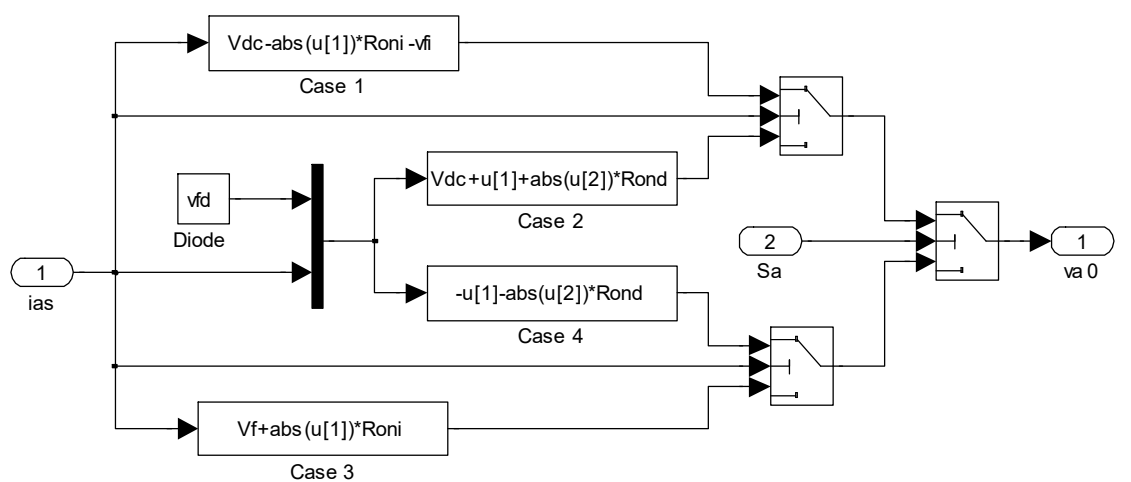

(a) MATLAB/Simulink model on one real VSI leg.

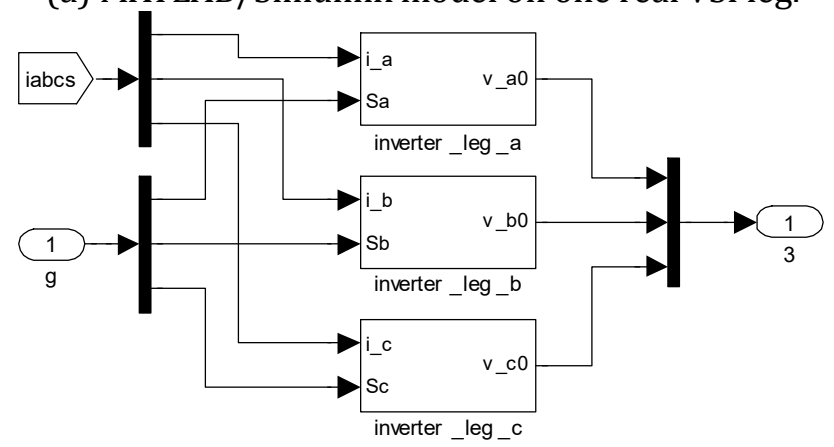

(b) MATLAB/Simulink model on three real VSI legs

Fig. 4. Analysis MATLAB/Simulink model of a proposed VSI. 
Base on Equations (7)-(9) and Equations (11)-(14), a MATLAB/Simulink model on one real VSI leg is developed as shown in Fig. 4(a). Also, Fig. 4(b) shows a MATLAB/Simulink model of VSI having its voltage drops.

\section{Mathematical Model of Three-Phase Induction Motors}

\subsection{Voltage Equations}

The voltage equations with respect to machine variables may be expressed as

$$
\begin{gathered}
\boldsymbol{v}_{s}=R_{s} \boldsymbol{i}_{s}+\frac{d \lambda_{s}}{d t}+j \omega \lambda_{s} \\
\boldsymbol{v}_{r}=R_{r} \boldsymbol{i}_{r}+\frac{d \lambda_{r}}{d t}+j\left(\omega-\omega_{r}\right) \lambda_{r}
\end{gathered}
$$

where $\boldsymbol{v}_{s}$ and $\boldsymbol{v}_{r}$ are the stator and rotor voltage vectors, respectively; $\boldsymbol{i}_{s}$ and $\boldsymbol{i}_{r}$ are the stator and rotor current vectors, respectively; $\lambda_{s}$ and $\lambda_{r}$ are the stator and rotor flux linkage vectors, respectively; $R_{s}$ and $R_{r}$ are the stator and rotor winding resistance, respectively.

\subsection{Flux-Linkage Equations}

The flux-linkage equations may be expressed as

$$
\begin{aligned}
& \lambda_{s}=L_{s} \boldsymbol{i}_{s}+L_{m} \boldsymbol{i}_{r} \\
& \lambda_{r}=L_{r} \boldsymbol{i}_{r}+L_{m} \boldsymbol{i}_{s}
\end{aligned}
$$

where $L_{s}=L_{l s}+L_{m}$ represents the stator self-inductance; $L_{r}=L_{l r}+L_{m}$ represents the rotor self-inductance; $L_{l s}$ and $L_{l r}$ are the stator and rotor leakage inductances, respectively; and $L_{m}$ is the magnetizing inductance. Note that all the rotor parameters and variables, such as $R_{r}, L_{l r}, \boldsymbol{i}_{r}, \boldsymbol{i}_{r}$ and, in the above questions are referred to the stator side.

\subsection{Electromagnetic Torque Equation}

The electromagnetic torque equation, given

$$
T_{e}=\frac{3 P}{2} \frac{L_{m}}{\sigma L_{s} L_{r}} \lambda_{s} \lambda_{r} \sin \theta_{T}
$$

where $\mathrm{P}$ is the number of pole pairs.

\subsection{Motion Equation}

The motion equation, given

$$
\frac{d \omega_{r}}{d t}=\frac{P}{J}\left(T_{e}-T_{L}\right)
$$

where $J$ is the total moment of inertia of the rotor and load, $P$ is the number of pole pairs, $T_{L}$ is the load torque

\section{Direct Torque Control}

DTC is an advanced control method originally developed for induction machine drives, which is a good solution for medium and high power electrical drive applications. This method has advantage in terms of 
ease of implementation and less computation time. The DTC is characterized by the absence of PI regulators, coordinate transformations, current regulators, and PWM signals generators. However, the DTC presents some disadvantages that can be summarized in the following points such as difficulty to control torque and flux at very low speed, variable switching frequency behavior, high noise level at low speed, lack of direct current control. The principle and implementation of DTC are follows as

\subsection{Principle of Direct Torque Control}

The electromagnetic torque is given by the following equation

$$
T_{e}=\frac{3 P}{2} \frac{L_{m}}{\sigma L_{s} L_{r}} \lambda_{s} \lambda_{r} \sin \theta_{T}
$$

The dynamic of the stator flux vector is governed by the stator voltage equation expressed in the stationary reference frame, as follows

$$
\frac{d \lambda_{s}}{d t}=\boldsymbol{v}_{s}-R_{s} \boldsymbol{i}_{s}
$$

Neglecting the voltage drop $R_{s} \boldsymbol{i}_{s}$ across the stator resistance

$$
\frac{d \lambda_{s}}{d t}=\boldsymbol{v}_{s}
$$

The torque comparator as

$$
d T_{e}=\left\{\begin{array}{l}
1, \text { for } T_{e}^{*}-T_{e}>\frac{\Delta T_{e}}{2} \\
0, \text { for }-\frac{\Delta T_{e}}{2}<T_{e}^{*}-T_{e}<\frac{\Delta T_{e}}{2} \\
-1, \text { for } T_{e}^{*}-T_{e}<-\frac{\Delta T_{e}}{2}
\end{array}\right.
$$

The flux comparator as

$$
d\left|\varphi_{s}\right|=\left\{\begin{array}{l}
1, \text { for }\left|\varphi_{s}^{*}\right|-\left|\varphi_{s}\right|>\frac{\Delta \varphi}{2} \\
0, \text { for }\left|\varphi_{s}^{*}\right|-\left|\varphi_{s}\right|<-\frac{\Delta \varphi}{2}
\end{array}\right.
$$

\subsection{Stator Flux and Torque Calculation}

The stator voltage $\alpha$ component estimation equation to estimate the stator flux as follows

$$
v_{\alpha s}=R_{s} i_{\alpha s}+\frac{d \varphi_{\alpha s}}{d t}
$$

The stator flux $\alpha$ component estimation equation to estimate the stator flux as follows

$$
\varphi_{\alpha s}=\int\left(v_{\alpha s}-R_{s} i_{\alpha s}\right) d t
$$

The stator voltage $\beta$ component estimation equation to estimate the stator flux as follows

$$
v_{\beta s}=R_{s} i_{\alpha s}+\frac{d \varphi_{\beta s}}{d t}
$$

The stator flux $\beta$ component estimation equation to estimate the stator flux as follows 


$$
\varphi_{\beta s}=\int\left(v_{\beta s}-R_{s} i_{\beta s}\right) d t
$$

The electromagnetic torque estimation equation is given by the following equation

$$
T_{e}=\frac{3 p}{2}\left(\varphi_{\alpha s} i_{\beta s}-\varphi_{\beta s} i_{\alpha s}\right)
$$

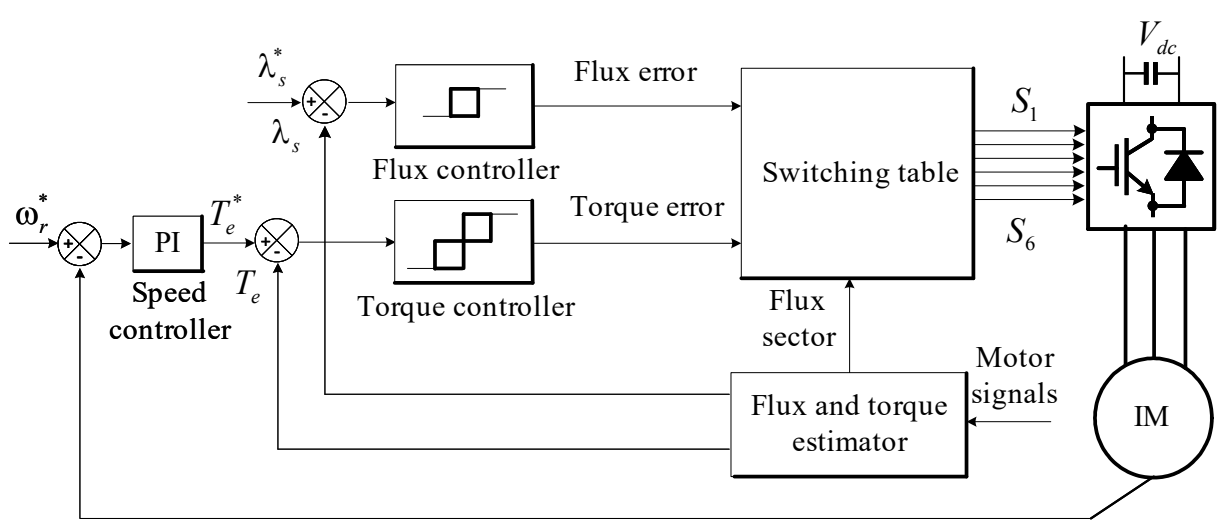

Fig. 5. DTC scheme for an induction motor drive.

Table 1. Motor Parameters

\begin{tabular}{llll}
\hline \hline Parameter & Symbol & Value & Unit \\
\hline Rated stator line-line voltage & $V_{n}$ & 380 & $\mathrm{~V}$ \\
Rated speed & $n_{r}$ & 1480 & $\mathrm{rpm}$ \\
Number of pole pairs & $P$ & 2 & \\
Rated stator frequency & $f$ & 50 & $\mathrm{~Hz}$ \\
Rated torque & $T_{n}$ & 26.5 & $\mathrm{~N} . \mathrm{m}$ \\
Stator winding resistance & $R_{s}$ & 1.37 & $\Omega$ \\
Rotor winding resistance & $R_{r}$ & 1.1 & $\Omega$ \\
Stator leakage inductance & $L_{l s}$ & 0.1459 & $\mathrm{H}$ \\
Rotor leakage inductance & $L_{r}$ & 0.149 & $\mathrm{H}$ \\
Magnetizing inductance & $L_{m}$ & 0.141 & $\mathrm{H}$ \\
Moment of inertia & $J$ & 0.1 & $\mathrm{~kg} \cdot \mathrm{m}^{2}$ \\
\hline \hline
\end{tabular}

Table 2. Parameters of Proposed Inverter

\begin{tabular}{llll}
\hline \hline Parameter & Symbol & Value & Unit \\
\hline Forward drop of IGBT & $v_{f i}$ & 1.8 & $\mathrm{~V}$ \\
On-state resistance of IGBT & $R_{\text {oni }}$ & 0.0694 & $\Omega$ \\
Forward drop of Diode & $v_{f d}$ & 1.75 & $\mathrm{~V}$ \\
On-state resistance of Diode & $R_{o n i}$ & 0.0694 & $\Omega$ \\
\hline \hline
\end{tabular}

The magnitude of stator flux linkage vector is given by

$$
\left|\varphi_{s}\right|=\sqrt{\varphi_{a s}^{2}+\varphi_{\beta s}^{2}}
$$

The angular position of stator flux linkage vector is given by

$$
\theta_{\varphi s}=\arctan \frac{\varphi_{\beta s}}{\varphi_{\alpha s}}
$$

\subsection{Control System}

The block diagram of the DTC control system for the IM is shown in Fig. 5. This block includes the DTC controller, a VSI, and a IM. 


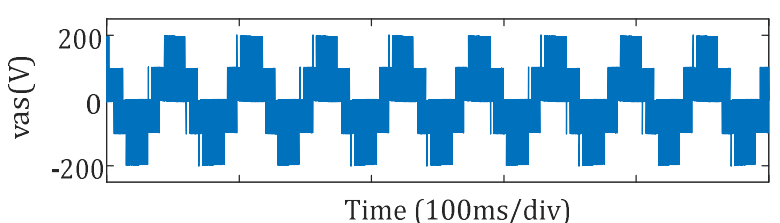

(a) $v_{a s}$

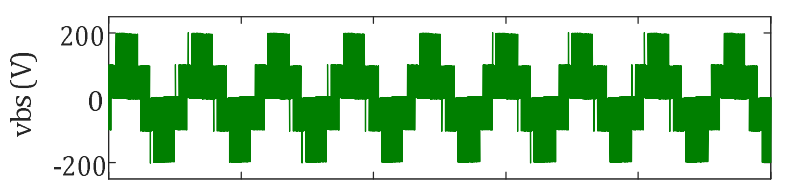

Time (100ms/div)

(b) $v_{b s}$

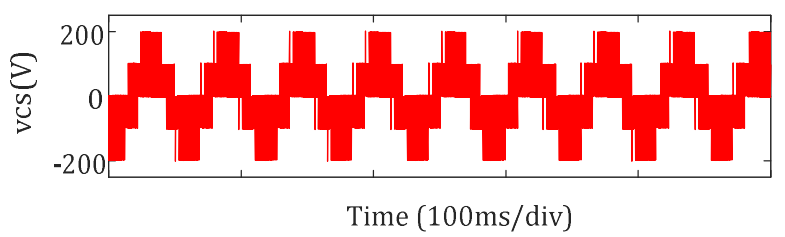

(c) $v_{c s}$

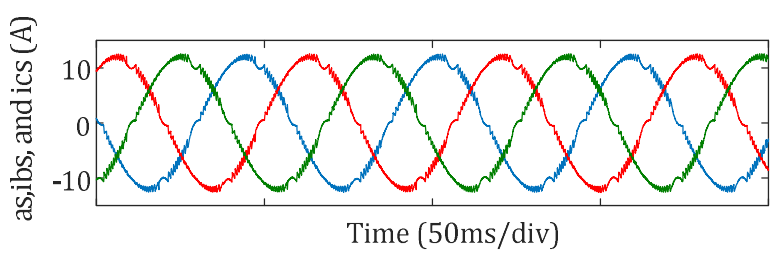

(d) Three-phase currents

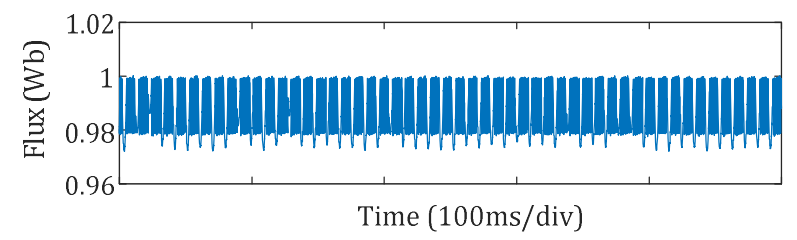

(e) Flux

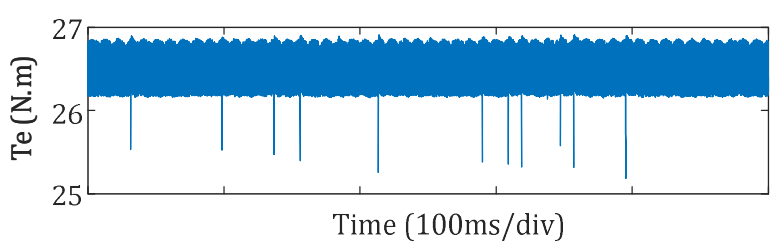

(f) Electromagnetic torque

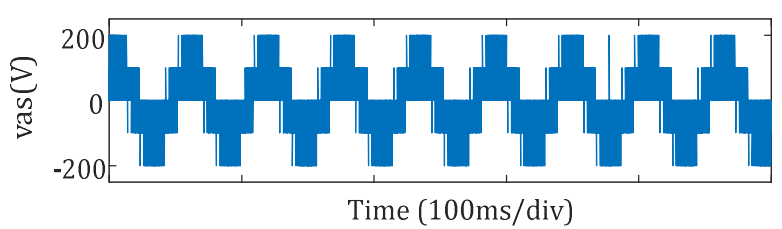

(a) $v_{a s}$

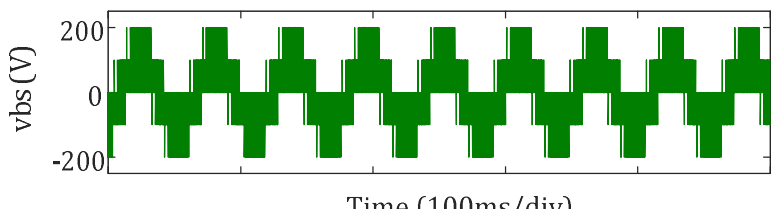

(b) $v_{b s}$

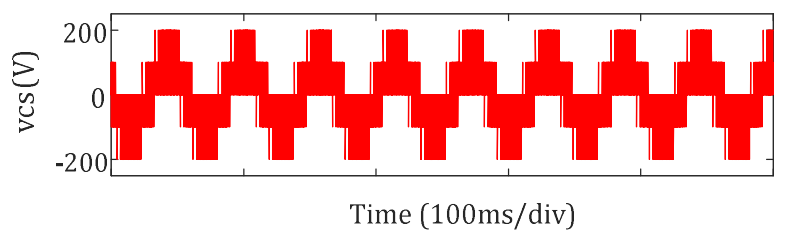

(c) $v_{c s}$

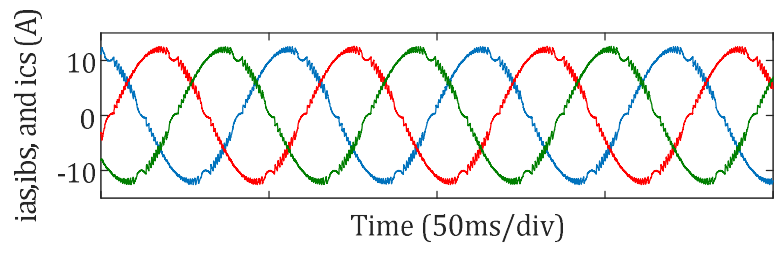

(d) Three-phase currents

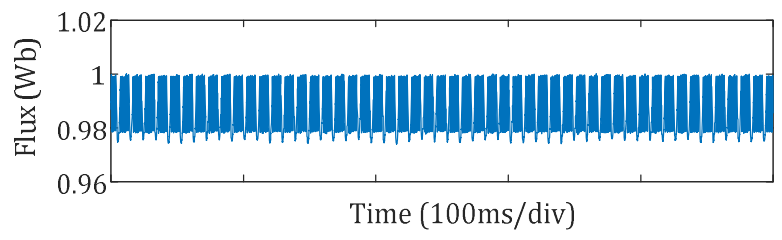

(e) Flux

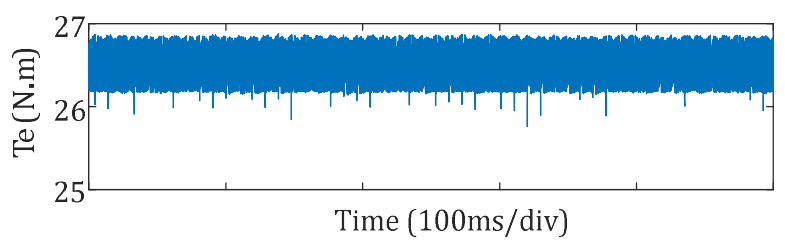

(f) Electromagnetic torque

Fig. 7. Performance analysis of ideal VSI.

Fig. 6. Performance analysis of proposed VSI.

\section{Simulated Studies}

In order to fully study the effect of the forward voltages drop of the power electronic devices in the power converter on the performance of a control system, comparative simulation studies were carried out by using MATLAB/Simulink. The simulation method uses Runge-Kutta algorithm with step size of $0.001 \mathrm{~ms}$. First, the MATLAB/Simulink model of IM is built based on its mathematical model which is shown in the section 4 . 
The parameters of the motor are given in Table 1. In the simulation, the stator flux linkage reference is set to $0.9889 \mathrm{~Wb}$. Also, the Electromagnetic torque reference is set to $2.65 \mathrm{~N} . \mathrm{m}$. The DC bus voltage of inverter is set to $300 \mathrm{~V}$. Table 2 shows parameters of proposed inverter.

The proposed inverter is compared to the ideal inverter in terms of its ability to DTC of IM by evaluating:

(a) The phase A output voltage waveform;

(b) The phase B output voltage waveform;

(c) The phase $\mathrm{C}$ output voltage waveform;

(d) The phase A, phase B, and phase C output voltage waveforms;

(e) Magnitude of stator flux linkage vector;

(f) Electromagnetic torque.

Fig. 6 shows a set of simulation waveforms for application DTC of IM with proposed inverter. Fig. 6(a) illustrates the proposed inverter output voltage waveform in phase A. Fig 6(b) illustrates the proposed inverter output voltage waveform in phase B. Fig. 6(c) illustrates the proposed inverter output voltage waveform in phase C. It is obvious from Fig. 6(a), Fig. 6(b), and Fig. 6(c) that reduction the voltage components.

Similarly, Fig. 7 shows a set of simulation waveforms for the ideal inverter study. Fig. 7 (a) illustrates the proposed inverter output voltage waveform in phase A. Fig. 7(b) illustrates the proposed inverter output voltage waveform in phase B. Fig. 7(c) illustrates the proposed inverter output voltage waveform in phase C. It is obvious from Fig. 7 that no reduction of the voltage components.

As can be seen in Figs. 6(f) and 7(f) that a higher electromagnetic torque ripple under the proposed inverter when compared to the ideal inverter case.

These simulation results confirm that the mathematical model of the VSI having its voltage drops is correct.

\section{Conclusion}

In this paper, a model of two-level three-phase voltage source inverter having its voltage drops is proposed. Then applicating to direct torque control of three-phase induction motors with the proposed model has studied. The proposal can be easily expanded to other applications.

\section{References}

[1] Vas, P., Sensorless Vector and Direct Torque Control. Oxford: Oxford University Press.

[2] Kazmierkowski, M., Krishnan, R., and Blaabjerg, F. (2002). Control in Power Electronics: Selected Problems. New York: Academic.

[3] Bose, B. K. (2006). Power Electronics and Motor Drives: Advances and Trends. Academic Press.

[4] Wu, B. (2006). High-Power Converters and AC Drives. Wiley-IEEE Press.

[5] Rashid, M. H. (2006). Power electronics handbook, $2^{\text {nd }}$ ed. New York: Academic.

[6] Bose, B. K. (2009). Power Electronics and Motor Drives Recent Progress and Perspective. IEEE Transactions on Industrial Electronics, 56(2), 581-588.

[7] Nam, K. H. (2010). AC motor control and electrical vehicle applications. CRC Press.

[8] Teodorescu R., Liserre M., \& Rodrıguez P. (2011). Grid converters for photovoltaic and wind power systems. IEEE Press.

[9] Hui, J. C. Y., Bakhshai A., and Jain P. K. (2016, July). An energy management scheme with power limit capability and an adaptive maximum power point tracking for small standalone PMSG wind energy systems. IEEE Transactions on Power Electronics, 31(7).

[10] Wei, S., Vittal, V. (2006). LP-based OPF for corrective FACTS control to relieve overloads and voltage 
violations, IEEE Transactions on Power Systems. 21(4), 1832-1839.

[11] Buja, G. S. and Kazmierkowski, M. P. (2004). Direct torque control of PWM inverter-fed AC motors-A survey. IEEE Transactions on Industrial Electronics, 51(4), 744-757.

[12] Khoa, D. Hoang., Zhu, Z. Q., and Martin, P. F. (2011). Influence and compensation of inverter voltage drop in direct torque-controlled four-switch three-phase PM brushless AC drives, IEEE Transactions on Power Electronics, 26(8), 2343-2357.

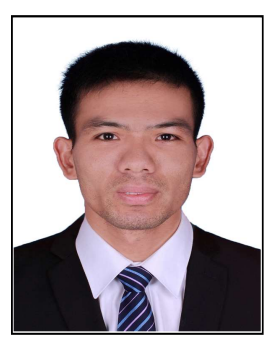

H. L. Bui received the B.Eng and M.S degrees in electrical engineering respectively from Hanoi University of Technology, Hanoi, Vietnam in 2001 and 2005. He is a lecturer in Department of Electrical Engineering, Hanoi University of Industrial, Vietnam. Now he is a Ph.D student of the College of Electrical and Information Engineering of Hunan University, China. His key research interests include power electronic converter for motor, wind power system, and solar power system.

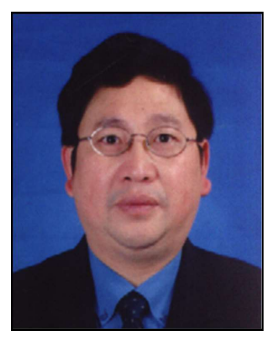

Shoudao Huang was born in China in 1962. He received a B.S. degree in Electric Machine and a Ph.D. degree in Electrical Engineering from Hunan University, China, in 1983 and 2000, respectively. From 1983 to 1993, he worked at the Hunan Motor factory as a technical Director. Since 1995, he has been with the College of Electrical and Information Engineering, Hunan University. From 2008 to 2009, he was a Visiting Scholar at the Energy College, Aalborg University, Denmark. He is currently a Vice President of the College of Electrical and Information Engineering, Hunan University, China. He is also an Executive Director of the Transactions of China Electrotechnical Society, a Director of the Hunan Association and Automation, a Director of the Energy Association of China, and a Committee Member of the large Motor Electrotechnical Society of China. His current research interests include power electronics and machine technology, control of power converters, wind power generation, and power quality.

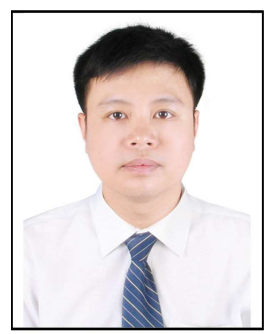

D. C. Pham received the B.Eng and M.Eng degrees from Ho Chi Minh City University of Technology, Ho Chi Minh, Vietnam, in 2001 and 2007, respectively, and the Ph.D. degree from Hunan University, China in 2012. He is a lecturer in Department of Electrical Engineering, Industrial University of Ho Chi Minh City. His key research interests include power electronics, electrical machines, and advanced control techniques for electrical drives. 